\title{
LEARNING AMID COVID-19: MEDICAL STUDENTS INVOLVEMENT IN PATIENT EDUCATION \& DISEASE AWARENESS
}

\author{
Segura-Azuara $\mathrm{NA}^{l *}$ and Lopez $\mathrm{M}^{1,2}$ \\ ${ }^{I}$ Tecnologico de Monterrey, Escuela de Medicina y Ciencias de la Salud, Mexico \\ ${ }^{2}$ Writing Lab, Institute for the Future of Education, Tecnologico de Monterrey, \\ Monterrey, Mexico
}

\begin{abstract}
The COVID-19 pandemic has nurtured meaningful transformations in educational contexts; even highly traditional contexts were open about transforming approaches and methodologies. Medical professionals' education relies heavily on presence-based interaction with patients, for example, to develop community activities such as patient education, which needed to continue despite the school lockdown. As part of an intervention, medical students designed a patient education and disease awareness campaign through social media. The objective of this study was to assess the transformation of patient education and disease awareness strategies to the new remote format. The methodology considered a quantitative approach with a descriptive, and crosssectional design. The sample consisted of 34 medical students enrolled in an endocrine diseases course. Each team designed the material for the campaign based on the literature research they performed. Three tutors evaluated each team using a 5-point Likert scale addressing: disease, posts, survey, and overall assessment. Analysis of results included mean, standard deviation, and linear regression. With a correlation coefficient of 0.745 and a standard error of 0.21 , the study found a high correlation between variables for each team. The results show that the transformation of this educational experience was key to offer an engaging educational learning experience for medical students. The campaigns held on social media platforms received a favorable response, as the engagement through comments and likes from their followers show, which helped on tunning the contents to relate closely to the specific audience.
\end{abstract}

Keywords: higher education, educational innovation, professional education, COVID-19 pandemic adaptations, patient education

\section{Introduction}

Aside from the specific and basic disciplinary concepts, like the Krebs citric acid cycle assembling chemically feasible reactions, or the latest research regarding novel therapy for new tropical diseases, medical schools focus on preparing their students professionally in the broadest meaning possible. Students must learn how to compassionately deliver bad news to patients and treat the patient as individuals with feelings, aspirations, fears, and challenges. Some of the so-called soft competencies are crucial for close interaction between patients and their physicians. Accordingly, health sciences programs provide appropriate learning environments for students to develop the necessary competencies for successful interaction with patients in real life. Each patient comes with their challenge to the clinician. Part of this challenge is educating the patient about their disease processes and how they can contribute to improving their health. During the COVID-19 pandemic, we face a more significant challenge: patient care must continue despite the school lockdown. 


\section{Literature Review}

\section{Patient education}

A significant paradigm shift in medicine is that physicians' role goes far beyond caring for patients, trying to prevent their community from getting even sick at all. To achieve this, their training must include patient education strategies that empower individuals to take care of their health. Every encounter between the physician and the patient is recognized as an opportunity to increase patient ownership and involvement in managing their health. Studies suggest patient education is one of the most important topics for physicians-in-training, as it helps the patient when they need it the most: before the patient even gets sick (Vijn et al., 2017). Here, one must be able not only to understand what is going on in the patient's body and mind, the pathophysiology of the disease but also to successfully communicate this information to the patient and his family in an understandable manner. This is challenging as the information should be simple and clear enough as for someone without a health sciences background to understand while still profound enough to fully empower them and make them allies in the healthcare system. If information is presented in a superficial and paternalistic vision, patients resent it. If it relies only on technical vocabulary, it might not fulfill its purpose. This big challenge for all requires competencies that must be achieved since the early years of medical school (A Leotsakos, 2014; Kutaimy et al., 2018).

Patient education has many faces: a direct conversation with the patient and his family members, community speeches, clinic events with specific diseases in mind to increase awareness and self-care, etc. (Friedman et al., 2016). Nurses, healthcare technicians, physicians, odontologists, nutritionists, etc. must all work in concert to achieve the best patient education in pursuit of improved clinical outcomes in their patients: better control, less complications, and decreased morbidity and mortality.

Patient education improves healthcare outcomes, with clinical benefits related to lifestyle interventions in diverse diseases, from endocrine to cardiovascular diseases (Paterick et al., 2017). Aside from medication, patient education is one of the most valuable tools for patient care in everyday activities. Strategies for patient and family education result in better adherence to therapy, earlier identification of signs associated with the disease, and overall decreased complications.

\section{Health Education Campaigns}

Health campaigns are usually community-based to promote wellbeing regardless of the participant's health status (Lee, 2019). Most of the campaign designs consider a face-to-face approach where different health professionals attend a particular region and provide care from the perspective of each of their specialties. By doing so, participants receive patient-centered and integrated care. This makes community members with particular risk factors for specific diseases to become aware of these and seek early medical advice, or it encourages participants to change specific modifiable risk factors to improve their health (Lee, 2019; National Sexual Violence Resource Center, 2010).

Some campaigns focus on the patient's family members. They are essential, as they provide support for the patient in his environment and can aid in changing family practices related to foods provided, exercise or encouragement in a scenario where the patients can be supported by the people surrounding them in their everyday life (Health Development Agency, 2004). Behavior change is 
reported to be accomplished through face-to-face interaction and with mass media use. Strategies in this area need to provide diverse contexts, for example, campaigns following a stepwise design are more effective (National Sexual Violence Resource Center, 2010).

\section{COVID-19 Adaptations}

The COVID-19 pandemic has nurtured meaningful transformations in educational contexts; even traditional contexts were open to accepting changes in approaches and methodologies.

COVID-19 pandemic has pushed medical education into different grounds, with directives having to make decisions rapidly and with little time to assess the risks. Teaching methodology changed overnight as the number of cases rose and spread globally, resulting in high mortality and dissemination of fear among the population worldwide (Wayne et al., 2020). Healthcare professionals were on the front line for facing this new threat with many doubts about what they faced and their decisions (Ahmed et al., 2020; Chick et al., 2020; Joseph et al., 2020). Teachers had to change their classrooms for computer-based teaching strategies in a short period. Some of them were not too much into technology, which also added to the problematic situation (Joseph et al., 2020; Wayne et al., 2020).

Patients, on the other side, were also caught in the middle of the profound changes in clinical practice. Many clinics rescheduled their regular patient visits and consultations, limited to predominantly emergency cases. As time went by, clinics introduced different strategies to stay in touch with their patients and continue their regular control, especially for chronic diseases like diabetes mellitus, hypertension, or coronary heart disease. Among these changes, regular patient education strategies were to adapt to the new reality (Patel et al., 2020). Social media and telemedicine solutions provided a platform for communication between healthcare members and the community. Under the current situation of limited social interaction in-person, these platforms arouse as a valuable tool by which patients and their families can receive information related to their disease (De Martino et al., 2017).

Particularly the continuity of disease awareness campaigns could benefit from the different adaptations that social media and other platforms could provide. Medical education was challenging, as presented in figure 1 its learning opportunities rely heavily on presence-based interaction for patient care or the development of community-driven activities such as patient education. These activities fulfill two very urgent and essential purposes at the same time. It benefits students' acquisition of skills and more deeply fulfills a social responsibility to society and to patient-centered care. Therefore, it was essential that medical schools promptly reimagine new formats for these dynamics to happen despite the COVID-19 pandemic (Figure 1). 


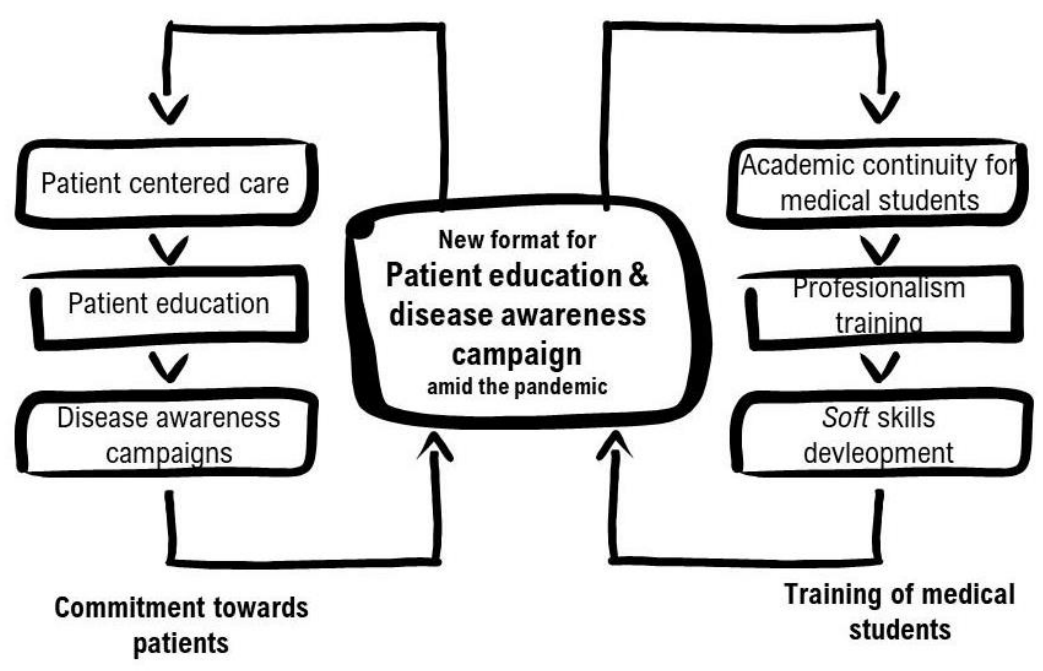

Figure 1: Representation of the two purposes of implementing a patient education and disease awareness campaign amid the COVID-19 pandemic.

As these activities benefit students' acquisition of skills and fulfill a social responsibility to society, medical schools needed to promptly reimagine new formats for these dynamics to be offered despite the COVID-19 pandemic. The objective of this study was to assess the transformation of patient education and disease awareness strategies to a new format amid the pandemic.

\section{Methods}

Regarding the methodology, a quantitative approach was implemented with a descriptive and crosssectional design (Hernández Sampieri et al., 2006). The sampling strategy considered a convenience sample of 34 students enrolled in the third year of the undergraduate medical program in the endocrine pathophysiology course. Participation was voluntary. If agreed to, they signed informed consent before participating in the study. The implementation occurred during the second semester of 2020 in a private Latin-American university.

To assess the developed strategy, an analysis is performed on the contribution as an educational learning experience through the products developed by the students. To do so, each team submitted a final report on the implementation and reflected the campaign contribution on their training as professionals.

As part of the development of the campaign, students received a briefing on the project objectives and the timeline for completion. The steps outlined for the project were: 1.- Audience Selection; 2.Objectives Description; 3.- Posts Development; 4.-Campaign Evaluation. Students were divided into four teams, and each team was assigned a highly prevalent endocrine disease: dyslipidemia, diabetes mellitus, hypothyroidism, and osteoporosis. These diseases are some of the most prevalent in Latin America and were aligned to the course objectives.

Each team could make between 20 and 25 posts. The length of the online campaign was limited to 1 week. Teams selected the audience they were going to target with the campaign: diagnosed patients, family members, undiagnosed patients, or people at risk. The audience selection determined the type 
of language to be used in the campaign and the design they were to include in the posts. Then they described the objectives of the specific campaign. Accordingly, their posts would serve these in a strategic plan to achieve the goal.

They conducted a thorough literature review to be familiar with the topic, looking for specific aspects to which their campaign would add value. Then they described the objectives of their campaign. Accordingly, teams identified specific aspects to include in the posts and order to capture the viewers' attention and lead the path they wanted them to follow in the campaign. Then, they decided what to include in each post and the number of posts for each day. Flexibility helped the audience to engage and provide a better understanding of the ideas to be transmitted.

Since social media provided the audience with the interactive tool of likes and shares, teams received ongoing feedback about their audience's behavior towards the campaign. At the end of the campaign, teams offered a survey for the audience to provide feedback (Figure 2).

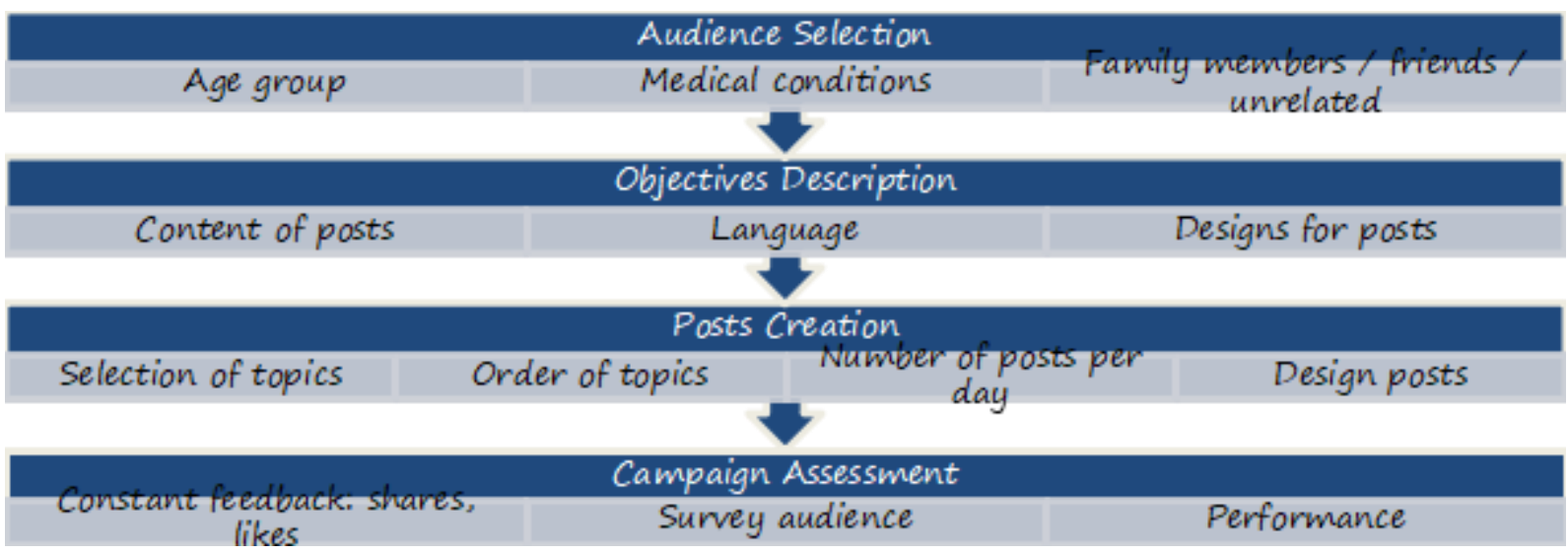

Figure 2: Campaign Design and Implementation Process.

\section{Results}

As a direct result of the implementation, four campaigns were held on a social media platform for one week. The assessment of their reports was performed following a rubric that included the evaluation of two parts, the disease presentation and the quality of designed posts (table 1). Three tutors scored their performance, considering a Likert scale from 1-5, where 1 stands for inadequate performance and 5 outstanding performance. The team with the best performance was the osteoporosis campaign with a mean of 4.33 , followed closely by the dyslipidemia campaign with a mean of 4.2. The team whose campaign had the lowest score was the one of diabetes mellitus with a 3.73 mean. In regression analysis of the number of elements included in their posts and the overall score obtained, there was a correlation coefficient of 0.745 , and a standard error of 0.21 . Therefore, there is a high correlation between both variables for each team. 
Table 1: Student teams' performance on the campaign.

\begin{tabular}{|c|c|c|c|c|c|c|c|c|c|c|}
\hline & \multicolumn{3}{|l|}{ Disease } & \multicolumn{3}{|l|}{ Posts } & \multirow[b]{2}{*}{$\begin{array}{l}\text { Survey } \\
\\
\text { Number of } \\
\text { responses, } \\
\text { engagement } \\
, \text { learning } \\
(\mathrm{n}=2)\end{array}$} & \multirow[b]{2}{*}{$\begin{array}{l}\text { Over } \\
\text { all }\end{array}$} & \multirow[b]{2}{*}{ Mean } & \multirow[b]{2}{*}{$\begin{array}{l}\text { Standard } \\
\text { Deviation }\end{array}$} \\
\hline Team & $\begin{array}{l}\text { Definition, } \\
\text { risk factors } \\
\text { and clinical } \\
\text { manifestati } \\
\text { ons }(n=3)\end{array}$ & $\begin{array}{l}\text { Classificati } \\
\text { on, } \\
\text { prevention, } \\
\text { diagnosis, } \\
\text { and } \\
\text { treatment } \\
(\mathrm{n}=4)\end{array}$ & $\begin{array}{l}\text { Etiology, } \\
\text { epidemiol } \\
\text { ogy, and } \\
\text { complicati } \\
\text { ons }(n=3)\end{array}$ & $\begin{array}{l}\text { Number, } \\
\text { colors } \\
\text { used, } \\
\text { insertions } \\
\text { (images, } \\
\text { GIFs, } \\
\text { video) } \\
(\mathrm{n}=5)\end{array}$ & $\begin{array}{l}\text { Amoun } \\
t \text { of } \\
\text { text, } \\
\text { langua } \\
\text { ge used } \\
(n=2)\end{array}$ & $\begin{array}{l}\text { Motivati } \\
\text { on, } \\
\text { applicati } \\
\text { on }(n=2)\end{array}$ & & & & \\
\hline dyslipidemia & 4.7 & 4.7 & 3.2 & 4.2 & 3 & 4.8 & 4.8 & 4.20 & 4.20 & 0.72 \\
\hline $\begin{array}{l}\text { diabetes } \\
\text { mellitus }\end{array}$ & 4.3 & 4 & 0 & 3.8 & 4.2 & 4.9 & 4.9 & 3.73 & 3.72 & 1.57 \\
\hline $\begin{array}{l}\text { hypothyroidi } \\
\text { sm }\end{array}$ & 4.3 & 4.6 & 2 & 4 & 4.3 & 4.7 & 4.6 & 4.07 & 4.07 & 0.87 \\
\hline osteoporosis & 4.6 & 2 & 4.3 & 5 & 4.9 & 4.9 & 4.6 & 4.33 & 4.32 & 0.98 \\
\hline Global & 4.48 & 3.98 & 2.38 & 4.25 & 4.1 & 4.83 & 4.73 & 3.61 & 4.04 & 0.78 \\
\hline
\end{tabular}

All the teams included posts related to the definition of the disease, risk factors, and clinical manifestations. $75 \%$ of the teams included information about disease classification, prevention, diagnosis, and treatment. Half of the teams included posts about etiology, epidemiology, and complications.

Two of the teams included GIFs in their posts. One of the teams included an interactive quiz. One team included a short video. The campaign with a younger target audience included a video and cartoons in their posts as to make the information friendlier to the participant. The target audience, in this case, was selected since effective measures against osteoporosis must be implemented since the young adult years, long before the disease starts, to have better chances of avoiding life-threatening complications.

The number of posts among the teams varied between 20 and 25 . The team with the most posts was focused on hypothyroidism; the team with the least posts was focused on diabetes mellitus. All the posts included a good design and color selection to attract online users. 2 teams included tables in their campaign related to diagnosis and classification, respectively.

The campaigns held in social media platform had a favorable response, as comments and likes from the audience show. From the implemented surveys in their campaign, a strong engagement was observed as they had 646 responses. The responses corresponded to $23.9 \%$ dyslipidemia, $23.5 \%$ diabetes mellitus, $23.2 \%$ hypothyroidism, and $29.2 \%$ osteoporosis.

\section{Discussion}

Since the social media platform was familiar to all students, it was easy for them to create engaging content. Still, we did not study a comparison between different social media platforms, which was more engaging for the audience, was easier to handle, or obtain better results on a final survey. These could be addressed in the future since the various platforms present differences in the audience, type of displays, and length of texts. Students performed thorough literature research to gather the pertinent information to include in their posts. With so much information available to include related to the disease, and a limited time for the campaign, teams prioritized the information. This was one of the complex tasks, according to their perception. Synthesis and analysis were categories crucial for the 
project, these are middle-top in Bloom's taxonomy, so they require a higher level of proficiency from the students.

The design and sequence followed in the posts was significantly related to the target audience. The younger the audience, they included more colorful and dynamic posts, while a more discrete design was used for the adult audience. Possibly, including students in the designing area could give significant input to the teams. Usually, health area students have little practice in creating original products. However, still, these type of activities helps to carry the students outside their comfort area, which is essential for a significant learning experience.

The data analysis for each team showed a high correlation between the number of elements included in the posts and the overall score, which shows that the more integral the posts were, the higher they scored. Each element contributed to the team's performance. Also, the higher number of audience responses to the survey, the higher the team's overall performance, demonstrating a high correlation among both variables. There is a high correlation (correlation coefficient of 0.74 ) between the total elements included in the posts and the overall performance, which shows that the richer the posts, the higher the scores and survey responses. The results showed that the transformation of this educational experience was vital to offer educational learning experiences for medical students amid the pandemic.

\section{Conclusion}

The social media resulted in a favorable platform for student teams to develop and launch their patient education and disease awareness campaign focused on endocrine-related diseases that were the target of the class - using a familiar platform for students to express their creativity made it possible for them to focus on the job instead of struggling with learning about the technologies and tools. Critical thinking for prioritizing information and their organization was reached by limiting the time and number of posts to include in the campaign. The design of posts was made with the target audience in mind; therefore, the type of posts differs accordingly. The project provided a valuable strategy for developing analytics, synthetic, teamwork, collaboration, communication, and integrative skills.

Limitations to our study include a small sample for the study, few tutors evaluating the performance, and limited time for campaign duration. All this can influence the results; therefore, a subsequent study in a different population, higher number of students, tutors, and other courses can yield broader information as to why the campaign is feasible and effective. The audience is limited to social media users, limiting the extent of the effect the campaign can have on the community. Further on, we advise as to implement a study with other social media platforms to compare the best to provide the campaign for the public.

For all students, this was the first time in which they designed a campaign in digital format. The use of technology for reaching out to patients and family members must be encouraged since early years in med school. The pandemic has made educators and institutions change the way the teachinglearning process is structured; some of these new ways should continue once social distancing is not required. It makes it possible to reach the community with important information that can be lifechanging in some cases. As patients understand better their disease, they are empowered to work hand in hand with the healthcare providers to benefit their quality of life and expectations. 


\section{References}

A Leotsakos, A., Ardolino, A., Cheung, R., Zheng, Hao, Barraclough, B., Walton, M. (2014). Educating future leaders in patient safety. $J$ Multidiscip Healthc, 7, 381-388. DOI: 10.2147/JMDH.S53792

Ahmed, H., Allaf, M., \& Elghazaly, H. (2020). COVID-19 and medical education. The Lancet Infectious Diseases, 20(7), 777-778. https://doi.org/10.1016/S1473-3099(20)30226-7

Chick, R. C., Clifton, G. T., Peace, K. M., Propper, B. W., Hale, D. F., Alseidi, A. A., \& Vreeland, T. J. (2020). Using Technology to Maintain the Education of Residents During the COVID-19 Pandemic. Journal of Surgical Education, 77(4), 729-732. https://doi.org/10.1016/j.jsurg.2020.03.018

De Martino, I., D’Apolito, R., McLawhorn, A. S., Fehring, K. A., Sculco, P. K., \& Gasparini, G. (2017). Social media for patients: benefits and drawbacks. Current Reviews in Musculoskeletal Medicine, 10 (1), 141-145. https://doi.org/10.1007/s12178-017-9394-7

Friedman, C. P., Donaldson, K. M., \& Vantsevich, A. V. (2016). Educating medical students in the era of ubiquitous information. Medical Teacher, 38(5), 504-509. https://doi.org/10.3109/0142159X.2016.1150990

Health Development Agency. (2004). The effectiveness of public health campaigns Background. HDA Briefing, 7, 1-5.

Hernández Sampieri, R., Fernández Collado, C., Baptista Lucio, P., \& Casas Pérez, M. D. L. L. (2006). Metodología de la Investigación. México: McGrawHill.

Joseph, J. P., Joseph, A. O., Conn, G., Ahsan, E., Jackson, R., \& Kinnear, J. (2020). COVID-19 Pandemic - Medical Education Adaptations: the Power of Students, Staff and Technology. Medical Science Educator, 30(4), 1355-1356. https://doi.org/10.1007/s40670-020-01038-4

Kutaimy, R., Zhang, L., Blok, D., Kelly, R., Kovacevic, N., Levoska, M., Gadivemula, R., \& Levine, D. (2018). Integrating patient safety education into early medical education utilizing cadaver, sponges, and an inter-professional team. BMC Medical Education, 18(1), 215. https://doi.org/10.1186/s12909-018-1325-9

Lee, S. W. H. (2019). Pharmacy student-led health education campaign initiative. Currents in Pharmacy Teaching and Learning, 11(3), 292-295. https://doi.org/10.1016/j.cpt1.2018.12.010

National Sexual Violence Resource Center. (2010). Creating an Effective Public Education Campaign. http://www.extension.iastate.edu/comm

Patel, S. M., Miller, C. R., Schiavi, A., Toy, S., \& Schwengel, D. A. (2020). The sim must go on: adapting resident education to the COVID-19 pandemic using telesimulation. Advances in Simulation, 5(1), 26. https://doi.org/10.1186/s41077-020-00146-w

Paterick, T. E., Patel, N., Tajik, A. J., \& Chandrasekaran, K. (2017). Improving Health Outcomes Through Patient Education and Partnerships with Patients. Baylor University Medical Center Proceedings, 30(1), 112-113. https://doi.org/10.1080/08998280.2017.11929552

Vijn, T. W., Fluit, C. R. M. G., Kremer, J. A. M., Beune, T., Faber, M. J., \& Wollersheim, H. (2017). Involving Medical Students in Providing Patient Education for Real Patients: A Scoping Review. Journal of General Internal Medicine, 32(9), 1031-1043. https://doi.org/10.1007/s11606-017-4065-3

Wayne, D. B., Green, M., \& Neilson, E. G. (2020). Medical education in the time of COVID-19. In Science Advances (Vol. 6, Issue 31, p. eabc7110). American Association for the Advancement of Science. https://doi.org/10.1126/sciadv.abc7110 